\title{
Risk of severe outcomes among patients admitted to hospital with pandemic (H1N1) influenza
}

\author{
Alexia Campbell MHSc, Rachel Rodin MD MPH, Rhonda Kropp BScN MPH, Yang Mao PhD, \\ Zhiyong Hong MD DrPH, Julie Vachon BSc, John Spika MD, Louise Pelletier MD MPH
}

Previously published at www.cmaj.ca

\section{ABSTRACT}

Background: We describe the disease characteristics and outcomes, including risk factors for admission to intensive care unit (ICU) and death, of all patients in Canada admitted to hospital with pandemic (H1N1) influenza during the first five months of the pandemic.

Methods: We obtained data for all patients admitted to hospital with laboratory-confirmed pandemic (H1N1) influenza reported to the Public Health Agency of Canada from Apr. 26 to Sept. 26, 2009. We compared inpatients who had nonsevere disease with those who had severe disease, as indicated by admission to ICU or death.

Results: A total of 1479 patients were admitted to hospital with confirmed pandemic (H1N1) influenza during the study period. Of these, $1171(79.2 \%)$ did not have a severe outcome, $236(16.0 \%)$ were admitted to ICU and survived, and $72(4.9 \%)$ died. The median age was 23 years for all of the patients, 18 years for those with a nonsevere outcome, 34 years for those admitted to ICU who survived and 51 years for those who died. The risk of a severe outcome was elevated among those who had an underlying medical condition and those 20 years of age and older. A delay of one day in the median time between the onset of symptoms and admission to hospital increased the risk of death by $5.5 \%$. The risk of a severe outcome remained relatively constant over the five-month period.

Interpretation: The population-based incidence of admission to hospital with laboratory-confirmed pandemic (H1N1) influenza was low in the first five months of the pandemic in Canada. The risk of a severe outcome was associated with the presence of one or more underlying medical conditions, age of 20 years or more and a delay in hospital admission.

$\mathrm{T}$ he first cases of pandemic (H1N1) influenza in Canada were reported on Apr. 26, 2009. Retrospective case-finding determined that the onset of symptoms in the first Canadian case, involving a traveller returning from Mexico, occurred on Apr. 12, 2009. The first patient admitted to hospital began to experience symptoms on Apr. 18.

During the first few weeks of the outbreak, in-depth follow-up and reporting of cases was conducted in keeping with the World Health Organization's pandemic plans for each country to comprehensively assess its first 100 cases. $^{1}$ By mid-May, many Canadian jurisdictions moved away from this approach because it became increasingly taxing on both public health human resources and laboratory capacity. It was decided that reporting of individual cases would continue nationally only for patients who were admitted to hospital or who died. We provide a detailed review of the disease characteristics and outcomes, including risk factors for admission to intensive care unit (ICU) and death, of patients admitted to hospital in Canada during the first five months of the pandemic.

\section{Methods}

\section{Ascertainment of cases}

All 13 provinces and territories in Canada participated in an active national surveillance system that captured all cases of laboratory-confirmed pandemic (H1N1) influenza in patients admitted to hospital or who died and then reported them to the Public Health Agency of Canada. A laboratory-confirmed case was defined as one involving a person with pandemic (H1N1) influenza, with or without clinical symptoms, that was confirmed by one or more of the following tests: reverse transcription polymerase chain reaction, viral culture, or test for antibodies against pandemic (H1N1) influenza virus showing four-fold rise in antibody levels. Probable or suspect cases were not nationally reportable. This case definition was consistent over the study period.

Patients admitted to hospital were prioritized for laboratory testing, so case ascertainment was also relatively consistent over the study period. In the first six weeks of the pandemic, the Public Health Agency of Canada recommended testing for the pandemic (H1N1) influenza virus in patients with influenza-like illness (in the community and in hospital)

From the Centre for Immunization and Respiratory Infectious Diseases, Infectious Disease and Emergency Preparedness Branch (Campbell, Rodin, Vachon, Spika, Pelletier); Chronic Disease Risk Assessment, Health Promotion and Chronic Disease Prevention Branch (Mao); and the Centre for Communicable Diseases and Infection Control, Infectious Disease and Emergency Preparedness Branch (Kropp, Hong), Public Health Agency of Canada, Ottawa, Ont.

CMAJ 2010. DOI:10.1503/cmaj.091823 
to facilitate characterization of the epidemiologic features, clinical presentation and outcomes associated with this novel virus. ${ }^{2}$ A general shift to laboratory testing of only patients with severe illness and those admitted to hospital occurred by mid-June. Testing of samples from patients in the community continued to varying degrees depending on provincial policies and laboratory capacity.

In this article, we report on confirmed cases involving patients admitted to hospital that were reported to the Public Health Agency of Canada from Apr. 26 to Sept. 26, 2009.

\section{Collection of data}

Each week, the provincial and territorial surveillance partners submitted lists of hospital cases and deaths. These lists contained the following core data: a unique case identifier, the reporting province or territory, the province or territory of residence, age, sex, Aboriginal status (defined as First Nations, Métis or Inuit), pregnancy status, presence or absence of underlying medical conditions known to predispose individuals to complications of influenza, ${ }^{3,4}$ mechanical ventilation, admission to ICU and death. For our study, we defined patients admitted to hospital who subsequently were admitted to ICU or who died as having a severe outcome. We considered all of the other patients admitted to hospital to have a nonsevere outcome.

\section{Statistical analysis}

We conducted a descriptive analysis of cases by age, sex, Aboriginal status, pregnancy status and presence or absence of underlying medical conditions. Because Ontario and Nova Scotia did not report Aboriginal status, we excluded data from those provinces for Aboriginal-specific calculations. We removed missing and unknown information from all calculations except for those on underlying medical conditions; where data on underlying conditions were missing (Ontario and Manitoba), we assumed that it reflected no underlying condition. We compared inpatients who had a nonsevere outcome with inpatients who were admitted to ICU and survived, those who died and those who had either severe outcome using univariable analysis and multivariable logistic regression analysis. The factors included in the multivariable models were sex, age (categorical) and the presence or absence of underlying medical conditions. Owing to a high degree of missing data on Aboriginal status, we did not include this characteristic in the multivariable analysis. We calculated the incidence of outcomes by age, sex, Aboriginal status, pregnancy status, and province or territory. We did not include patient-level information on antiviral treatment or influenza vaccination in our analyses because it was not available.

We examined differences in time to hospital admission by

Table 1: Characteristics of 1479 patients admitted to hospital with laboratory-confirmed pandemic (H1N1) influenza reported from Apr. 26 to Sept. 26, 2009, and risk of severe outcome

\begin{tabular}{|c|c|c|c|c|c|c|c|}
\hline \multirow[b]{2}{*}{ Characteristic } & \multirow{2}{*}{$\begin{array}{c}\text { Nonsevere } \\
\text { outcome, no. (\%) } \\
\text { of patients } \\
n=1171\end{array}$} & \multicolumn{2}{|c|}{ Admission to ICU, nonfatal } & \multicolumn{2}{|c|}{ Death } & \multicolumn{2}{|c|}{ Any severe outcomet } \\
\hline & & $\begin{array}{c}\text { No. }(\%) \\
\text { of patients } \\
n=236\end{array}$ & $\operatorname{RR}(95 \% \mathrm{Cl})$ * & $\begin{array}{c}\text { No. }(\%) \\
\text { of patients } \\
n=72\end{array}$ & $\operatorname{RR}(95 \% \mathrm{Cl}) *$ & $\begin{array}{c}\text { No. }(\%) \\
\text { of patients } \\
n=308\end{array}$ & $\operatorname{RR}(95 \% \mathrm{Cl})$ * \\
\hline Sex, female & $581 / 1169(49.7)$ & $135 / 236(57.2)$ & $1.3(1.0-1.6)$ & $43 / 72(59.7)$ & $1.5(0.9-2.3)$ & $178 / 308(57.8)$ & $1.3(1.1-1.6)$ \\
\hline \multicolumn{8}{|l|}{ Age, yr } \\
\hline$<1$ & $111 / 1166 \quad(9.5)$ & $11 / 235 \quad(4.7)$ & $0.7(0.3-1.4)$ & $1 / 72 \quad(1.4)$ & $0.3(0.1-2.5)$ & $12 / 307 \quad(3.9)$ & $0.6(0.3-1.2)$ \\
\hline $1-4$ & $168 / 1166(14.4)$ & $17 / 235 \quad(7.2)$ & $0.7(0.4-1.3)$ & $0 / 72$ & NA & $17 / 307 \quad(5.5)$ & $0.6(0.3-1.1)$ \\
\hline $5-9$ & 159/1166 (13.6) & $14 / 235 \quad(6.0)$ & $0.6(0.3-1.2)$ & $3 / 72 \quad(4.2)$ & $0.6(0.1-2.5)$ & $17 / 307 \quad(5.5)$ & $0.6(0.3-1.1)$ \\
\hline $10-19$ & $157 / 1166(13.5)$ & $23 / 235 \quad(9.8)$ & Reference & $5 / 72 \quad(6.9)$ & Reference & $28 / 307 \quad(9.1)$ & Reference \\
\hline $20-44$ & 277/1166 (23.8) & $86 / 235(36.6)$ & $2.1(1.3-3.5)$ & $18 / 72(25.0)$ & $2.0(0.7-5.6)$ & 104/307 (33.9) & $2.1(1.3-3.3)$ \\
\hline $45-64$ & $210 / 1166(18.0)$ & 69/235 (29.4) & $2.2(1.3-3.8)$ & $27 / 72$ (37.5) & $4.0(1.5-10.7)$ & 96/307 (31.3) & $2.6(1.6-4.1)$ \\
\hline$\geq 65$ & $84 / 1166 \quad(7.2)$ & $15 / 235 \quad(6.4)$ & $1.2(0.6-2.5)$ & $18 / 72(25.0)$ & $6.7(2.4-18.8)$ & 33/307 (10.7) & $2.2(1.3-3.9)$ \\
\hline Aboriginal & $215 / 859 \quad(25.0)$ & $37 / 179(20.7)$ & $0.8(0.6-1.1)$ & $9 / 50(18.0)$ & $0.7(0.3-1.4)$ & $46 / 229(20.1)$ & $0.8(0.6-1.1)$ \\
\hline Pregnant & $61 / 126 \quad(48.4)$ & $13 / 36 \quad(36.1)$ & $0.7(0.4-1.2)$ & $4 / 8 \quad(50.0)$ & $1.1(0.3-4.1)$ & $17 / 44(38.6)$ & $0.7(0.4-1.3)$ \\
\hline $\begin{array}{l}\geq 1 \text { underlying } \\
\text { medical conditions§ }\end{array}$ & 479/1071 (44.7) & $126 / 217(58.1)$ & $1.6(1.2-2.0)$ & $49 / 70(70.0)$ & $2.7(1.7-4.5)$ & $175 / 287(61.0)$ & $1.7(1.4-2.1)$ \\
\hline $\begin{array}{l}\text { Pre-existing heart } \\
\text { disease }\end{array}$ & $80 / 1049 \quad(7.6)$ & $35 / 209(16.7)$ & $2.0(1.5-2.7)$ & $16 / 65(24.6)$ & $3.5(2.1-5.9)$ & $51 / 274(18.6)$ & $2.1(1.6-2.7)$ \\
\hline Diabetes mellitus & $82 / 1047 \quad(7.8)$ & $42 / 211$ (19.9) & $2.3(1.7-3.0)$ & $13 / 65(20.0)$ & $2.7(1.5-4.7)$ & $55 / 276(19.9)$ & $2.2(1.7-2.7)$ \\
\hline Renal disease & $51 / 1044 \quad(4.9)$ & $14 / 204 \quad(6.9)$ & $1.3(0.8-2.2)$ & $7 / 64$ (10.9) & $2.2(1.1-4.7)$ & $21 / 268 \quad(7.8)$ & $1.5(1.0-2.1)$ \\
\hline Immunosuppression & 93/1041 (8.9) & $21 / 200(10.5)$ & $1.2(0.8-1.7)$ & $17 / 64(26.6)$ & $3.3(2.0-5.5)$ & $38 / 264(14.4)$ & $1.5(1.1-2.0)$ \\
\hline $\begin{array}{l}\text { Lung disease } \\
\text { (including asthma) }\end{array}$ & $309 / 738 \quad(41.9)$ & 73/154 (47.4) & $1.2(0.9-1.6)$ & $30 / 52(57.7)$ & $1.8(1.1-3.1)$ & $103 / 206(50.0)$ & $1.3(1.0-1.6)$ \\
\hline
\end{tabular}

Note: $\mathrm{Cl}=$ confidence interval, $\mathrm{ICU}=$ intensive care unit, $\mathrm{NA}=$ not applicable, $\mathrm{RR}=$ relative risk

*For comparison with admission to hospital with nonsevere illness.

tAdmission to ICU or death.

¥Pregnancy among women of childbearing age (15-44 years of age).

§Includes lung disease, asthma, diabetes and other metabolic disorders, pre-existing heart disease, renal disease, immunosuppression, anemia, liver disease, neurologic disorder, or other chronic medical condition predisposing to complications of influenza. ${ }^{3,4}$ 
severity of outcome. In addition, we looked at the risk of a severe outcome by age among patients without an underlying medical condition. For these analyses, we combined both types of severe outcome (admission to ICU and death) because of the small number of cases. We calculated population denominators using Statistics Canada census, pregnancy outcome and live-birth estimates..$^{5-8}$

\section{Results}

Between Apr. 26 and Sept. 26, 2009, 1479 cases of patients admitted to hospital with laboratory-confirmed pandemic (H1N1) influenza were reported to the Public Health Agency of Canada. Of these, 1171 (79.2\%) did not have a severe outcome, $236(16.0 \%)$ were admitted to ICU and survived, and $72(4.9 \%)$ died (Table 1$)$. The incidence of admission to hospital without a severe outcome (3.47 per 100000 population), nonfatal admission to ICU (0.70 per $100000)$ and death (0.21 per 100000$)$ remained low during the study period (Table 2). ${ }^{9,10}$ Five additional deaths involved people who were not reported as having been admitted to hospital; we did not include these cases in the current analyses.

\section{Sex}

Females accounted for $51.4 \%(759 / 1477)$ of the patients. The risk of admission to ICU was greater among females than among males in the univariable analysis (Table 1); this difference disappeared in the multivariable analysis (Table 3).

Table 2: Incidence of nonsevere and severe outcomes among 1479 patients admitted to hospital with pandemic (H1N1) influenza, by sex, age, Aboriginal status and pregnancy status

\begin{tabular}{|crccc}
\hline & & \multicolumn{3}{c}{$\begin{array}{c}\text { Outcome; incidence } \\
\text { per } 100 \text { 000 population }\end{array}$} \\
\cline { 3 - 5 } & & $\begin{array}{c}\text { Nonsevere } \\
\text { outcome } \\
n=1171\end{array}$ & $\begin{array}{c}\text { Admission to } \\
\text { ICU, nonfatal } \\
n=236\end{array}$ & $\begin{array}{c}\text { Death } \\
n=72\end{array}$ \\
\hline Characteristic & Population & 3.47 & 0.70 & 0.21 \\
\hline Canada & 33739859 & & & \\
\hline Sex & & 3.50 & 0.60 & 0.17 \\
\hline Male & 16732476 & & 0.79 & 0.25 \\
\hline Female & 17007383 & 3.42 & & \\
\hline Age, yr & & & 2.92 & 0.27 \\
\hline$<1$ & 376842 & 29.46 & 1.16 & 0.00 \\
\hline $1-4$ & 1460882 & 11.50 & 0.78 & 0.17 \\
\hline $5-9$ & 1799302 & 8.84 & 0.54 & 0.12 \\
\hline $10-19$ & 4226705 & 3.71 & 0.73 & 0.15 \\
\hline $20-44$ & 11718791 & 2.36 & 0.73 & 0.29 \\
\hline $45-64$ & 9469891 & 2.22 & 0.32 & 0.38 \\
\hline$\geq 65$ & 4687446 & 1.79 & 4.08 & 0.99 \\
\hline Aboriginal & 906125 & 23.73 & 2.59 & 0.80 \\
\hline Pregnant & $501504 *$ & 12.16 & \\
\hline
\end{tabular}

*Estimated number of pregnant women in the five-month study period.

\section{Age}

On average, patients with a nonsevere outcome were younger than those admitted to ICU, who in turn were younger than those who died (Figure 1). The median age was 23 years for all of the patients, 18 years for those with a nonsevere outcome, 34 years for those admitted to ICU who survived and 51 years for those who died. Compared with patients aged 10-19 years, those aged 20-64 years were significantly more likely to be admitted to ICU, and those aged 45 years or more were significantly more likely to die, even after adjustment for sex and underlying medical conditions (Tables 1 and 3). Despite higher populationbased rates among children, inpatients at greatest risk for a severe outcome were those 20 years of age and older (Tables 1 and 3). Patients less than five years old had the highest population-based incidence of hospital admission without a severe outcome and of admission to ICU; they were followed closely by children five to nine years old (Table 2). Patients aged 65 or more had the lowest incidence of hospital admission without a severe outcome (1.79 per 100000 population) and the highest rate of death $(0.38$ per 100 000); patients aged 45-64 years had the next highest rate of death $(0.29$ per 100000$)$.

\section{Aboriginal status}

Aboriginal status was reported for $24.0 \%$ (261/1088) of the patients. The proportion of Aboriginal patients did not differ significantly between those with a nonsevere outcome and

Table 3: Factors associated with severe outcome in relation to nonsevere outcome among patients admitted to hospital with pandemic (H1N1) influenza

\begin{tabular}{|cccc}
\hline & \multicolumn{3}{c}{ Severe outcome; adjusted OR $(95 \% \mathrm{Cl})^{*}$} \\
\cline { 2 - 4 } & $\begin{array}{c}\text { Admission to } \\
\text { ICU, nonfatal }\end{array}$ & Death & Any \\
\hline Sex & & & \\
\hline Female & $1.3(0.9-1.7)$ & $1.3(0.8-2.1)$ & $1.3(0.9-1.3)$ \\
\hline Male & Reference & Reference & Reference \\
\hline Age, yr & & & \\
\hline$<1$ & $0.9(0.4-2.1)$ & $0.5(0.1-4.4)$ & $0.8(0.4-1.8)$ \\
\hline $1-4$ & $0.7(0.4-1.5)$ & NA & $0.6(0.3-1.2)$ \\
\hline $5-9$ & $0.6(0.3-1.3)$ & $0.8(0.2-3.5)$ & $0.6(0.3-1.3)$ \\
\hline $10-19$ & Reference & Reference & Reference \\
\hline $20-44$ & $2.2(1.3-3.8)$ & $2.6(0.9-7.8)$ & $2.3(1.4-3.7)$ \\
\hline $45-64$ & $2.3(1.3-4.0)$ & $4.2(1.4-12.6)$ & $2.6(1.5-4.3)$ \\
\hline$\geq 65$ & $1.1(0.5-2.3)$ & $7.0(2.3-21.7)$ & $2.1(1.2-3.9)$ \\
\hline 1 underlying & $1.5(1.1-2.1)$ & $1.6(0.9-2.9)$ & $1.5(1.1-2.1)$ \\
\hline medical conditionst & & & \\
\hline
\end{tabular}

Note: $\mathrm{Cl}=$ confidence interval, $\mathrm{ICU}=$ intensive care unit, $\mathrm{NA}=$ not applicable, $\mathrm{OR}=$ odds ratio.

*Adjusted for sex, age and presence or absence of underlying medical conditions.

tIncludes lung disease, asthma, diabetes and other metabolic disorders, pre-existing heart disease, renal disease, immunosuppression, anemia, liver disease, neurologic disorder, or other chronic medical condition predisposing to complications of influenza., 
those with a severe outcome (Table 1). The Aboriginal population did experience a much higher incidence of nonsevere and severe outcomes than the general population (Table 2).

\section{Underlying medical conditions}

In this cohort, $48.2 \%$ of the patients had one or more underlying medical conditions. This characteristic was associated with an increased risk of a severe outcome even after adjustment for age and sex (Tables 1 and 3). The risk of a severe outcome was greatest among patients with diabetes (relative risk [RR] 2.2, 95\% confidence interval [CI] 1.7-2.7) and those with pre-existing heart disease (RR 2.1, 95\% CI 1.62.7), followed by those with immunosuppression (RR 1.5, 95\% CI 1.1-2.0). Lung disease, including asthma, was the most common underlying condition and was associated with an elevated risk of death (RR 1.8, 95\% CI 1.1-3.1).

For patients who had no underlying condition and were not pregnant, the risk of a severe outcome was greatest among those 30-49 years old and those 60 years and older (Table 4). Mechanical ventilation was required in $15.7 \%$ (153/977) of the patients. The rate of mechanical ventilation was lower among those with a nonsevere outcome (1.3\%) than among those with a severe outcome (65.0\%).

\section{Pregnancy status}

Of the 170 women in the study cohort who were of childbearing age (15-44 years), 78 (45.9\%) were pregnant. The pregnant women were not at increased risk of admission to ICU or death compared with the 92 nonpregnant women of reproductive age, but they did have a higher incidence of hospital admission without a severe outcome (12.16 v. 0.94 per 100000 population), admission to ICU (2.59 v. 0.33 per $100000)$ and death $(0.80$ v. 0.05 per 100000$)$ compared with the nonpregnant women of childbearing age.

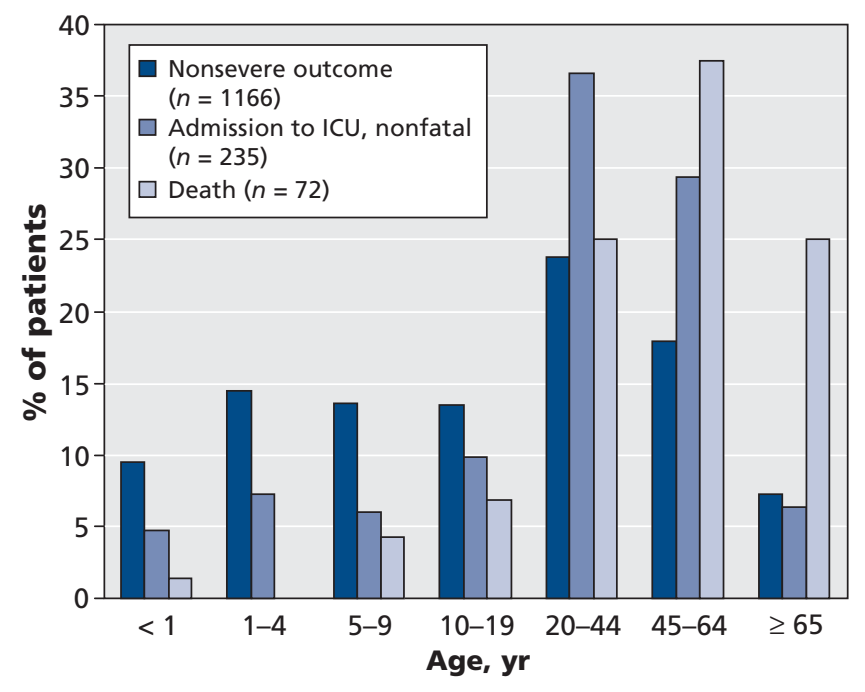

Figure 1: Severity of outcome by age among 1473 cases of pandemic (H1N1) influenza in patients admitted to hospital that were reported from Apr. 26 to Sept. 26, 2009. (Information on age missing for six patients.) ICU = intensive care unit.

\section{Time to hospital admission}

The median time from symptom onset to hospital admission was two to three days. Overall, a one-day difference in the median time to hospital admission increased the risk of death by $5.5 \%$. The median time from symptom onset to death, available for 41 patients, was 12 days (range 1-75).

\section{Geography and time}

June was the month in which the majority of patients were admitted to hospital (63.5\% [667/1050]) or reported symptom onset (64.7\% [941/1454]). The proportion of inpatients who experienced a severe outcome was relatively constant throughout the study period (mean 20.8\%, range 18\%-23\%, Figure 2). The median age of patients with a severe outcome did not change significantly between April and September 2009. The epidemic curve (Figure 2) predominantly reflects the evolution of the pandemic in Quebec, Ontario, Manitoba and Alberta, where the greatest number of hospital admissions were reported.

The incidence rates of nonsevere outcome and admission to ICU were highest in Nunavut, the Northwest Territories, Manitoba and Quebec; the incidence of death was highest in Nunavut, Saskatchewan and Manitoba (Table 5). Because of the small number of cases in Nunavut and the Northwest Territories, the rates in those jurisdictions should be interpreted with caution.

\section{Interpretation}

The population-based incidence of admission to hospital with laboratory-confirmed pandemic (H1N1) influenza was low in the first five months of the pandemic in Canada. This experience is consistent with that of other countries. ${ }^{9-12}$ As in Canada, the highest rates of hospital admission in the United States, Australia and the United Kingdom were among children less than five years old. ${ }^{13-15}$ Cumulative rates of death during the study period were also low: in Canada 0.21 per 100000 population died, as compared with 0.19 confirmed deaths per 100000 in the United States. ${ }^{11}$ Rates of death in New Zealand, Australia, Chile, Paraguay, Argentina and South Africa, which experienced the first wave of the pandemic during their usual influenza season, ranged from 0.19 to 1.4 per 100000 over the same period. ${ }^{12}$

In Canada, the first wave of the pandemic had a geographically and chronologically heterogeneous distribution. However, the risk of a severe outcome among patients admitted to hospital remained relatively constant during the study period and is consistent with other reports that the period and point prevalence of admission to ICU among inpatients ranged from $12 \%$ to $20 \%{ }^{16,17}$ Requirements for mechanical ventilation may have been underreported through public health surveillance, since a Canadian study reported that $81 \%$ of patients admitted to ICU required mechanical ventilation. ${ }^{18}$ The demand for ventilators and ICU beds during the second wave may be mitigated by the availability of a vaccine and by earlier and broader use of antiviral agents.

The risk of a severe outcome was greatest among the inpatients who had one or more underlying medical conditions 
and those who were 20 years of age or older. Those aged 65 years and older were at greatest risk of death. Children less than 10 years old, pregnant women and Aboriginal people were not at increased risk of a severe outcome, despite the relatively high population-based incidence of these outcomes. This paradoxical finding may be related to pediatric, pregnant and Aboriginal patients being admitted with milder disease and thus a lower chance of a severe outcome, or to the fact that population-based rates are crude measures that combine both probability of exposure and probability of virulent infection. Children are considered key transmitters of influenza and responsible for seeding households with the infection, so their likelihood of exposure may have been higher in the first wave. ${ }^{19}$

The risk of death from seasonal influenza is highest among people 70 years of age or older, and hospital admissions because of seasonal influenza are highest among children less than two years old and adults over 65 years. ${ }^{3,20}$ In the case of pandemic (H1N1) influenza, hospital admissions and severe outcomes occurred in all age groups and in a much younger Canadian population than seasonal influenza typically does. The age distribution of patients admitted to hospital in Canada was similar to that in the United States, where the median age of patients admitted to hospital was 20 years and the median age of death was 37 years. ${ }^{4}$ In our study, children had the highest absolute risk of severe and nonsevere outcomes, perhaps because of the tendency for influenza attack rates to be highest among preschool and school-age children. ${ }^{19}$ In terms of the timing of the pandemic, the peak of the first wave coincided with a period when Canadian students were in school. Resolution of the first wave coincided with the beginning of the summer break in July. Although children congregate in other places in the summer, school breaks have been reported to slow or delay the impact of seasonal influenza and may have played a role in interrupting transmission. ${ }^{21}$ Patients 65 years of age and older experienced the lowest incidence of hospital admission without a severe outcome but the highest population-based rate and relative risk of death among those admitted to hospital. This finding suggests the possibility of varying levels of immunity in this age group or a reduced penetration of the virus into the elderly community in the first wave.
Our analysis confirmed that the presence of one or more underlying medical conditions known to predispose to complications of influenza contributed to an elevated risk of a severe outcome among patients with pandemic (H1N1) influenza. Further research is needed to stratify risk based on the severity of the underlying conditions to further focus recommendations for prevention and treatment. In our study, underlying lung disease was common in all three patient groups (those with a nonsevere outcome, those admitted to ICU and those who died), a

Table 4: Risk of severe outcome among inpatients with pandemic (H1N1) influenza who had no underlying medical condition, * by age

\begin{tabular}{lclcc}
\hline Age, yr & $\begin{array}{c}\text { No. (\%) with } \\
\text { nonsevere outcome }\end{array}$ & $\begin{array}{c}\text { No. (\%) with } \\
\text { severe outcomet }\end{array}$ & $\begin{array}{c}\text { Risk of severe outcome, } \\
\text { OR (95\% Cl) }\end{array}$ \\
\hline$<1$ & $81 / 92$ & $(88.0)$ & $7 / 11(63.6)$ & $0.6(0.2-1.6)$ \\
\hline $1-4$ & $104 / 149$ & $(69.8)$ & $8 / 14(57.1)$ & $0.5(0.2-1.4)$ \\
\hline $5-9$ & $84 / 148$ & $(56.8)$ & $7 / 15(46.7)$ & $0.6(0.2-1.6)$ \\
\hline $10-19$ & $85 / 151$ & $(56.3)$ & $12 / 25(48.0)$ & Reference \\
\hline $20-29$ & $68 / 126$ & $(54.0)$ & $14 / 41(34.1)$ & $1.5(0.6-3.4)$ \\
\hline $30-39$ & $41 / 91$ & $(45.1)$ & $20 / 38(52.6)$ & $3.5(1.5-7.7)$ \\
\hline $40-49$ & $36 / 109$ & $(33.0)$ & $13 / 51(25.5)$ & $2.6(1.1-6.1)$ \\
\hline $50-59$ & $32 / 106$ & $(30.2)$ & $10 / 48(20.8)$ & $2.2(0.9-5.6)$ \\
$\geq 60$ & $22 / 102$ & $(21.6)$ & $10 / 48(20.8)$ & $3.2(1.2-8.4)$ \\
\hline All & $553 / 1074(51.5)$ & $101 / 291(34.7)$ & \\
\hline
\end{tabular}

*Underlying condition includes lung disease, asthma, diabetes and other metabolic disorders, pre-existing heart disease, renal disease, immunosuppression, anemia, liver disease, neurological disorder, or other chronic medical condition predisposing to complications of influenza. ${ }^{3,4}$ Pregnant women were also removed from this analysis.

†Admission to ICU or death.

Table 5: Incidence of nonsevere and severe outcomes among 1479 patients admitted to hospital with pandemic (H1N1) influenza, by province and territory*

\begin{tabular}{|lcccc}
\hline & \multicolumn{4}{c}{ Outcome; incidence per 100000 population } \\
\cline { 2 - 5 } & $\begin{array}{c}\text { All patients } \\
n=1479\end{array}$ & $\begin{array}{c}\text { Nonsevere } \\
\text { outcome } \\
n=1171\end{array}$ & $\begin{array}{c}\text { Admission to } \\
\text { ICU, nonfatal } \\
n=236\end{array}$ & $\begin{array}{c}\text { Death } \\
n=72\end{array}$ \\
\hline Province/territory & 1.2 & 0.7 & 0.4 & 0.1 \\
\hline British Columbia & 3.5 & 2.7 & 0.7 & 0.2 \\
\hline Alberta & 2.3 & 1.2 & 0.8 & 0.4 \\
\hline Saskatchewan & 18.1 & 14.6 & 2.9 & 0.6 \\
\hline Manitoba & 2.9 & 2.3 & 0.4 & 0.2 \\
\hline Ontario & 7.4 & 6.0 & 1.1 & 0.3 \\
\hline Quebec & 0.3 & 0.1 & 0.1 & 0.0 \\
\hline New Brunswick & 1.8 & 1.0 & 0.7 & 0.1 \\
\hline Nova Scotia & 0.7 & 0.7 & 0.0 & 0.0 \\
\hline Prince Edward Island & 0.6 & 0.4 & 0.2 & 0.0 \\
\hline Newfoundland and Labrador & 0.0 & 0.0 & 0.0 & 0.0 \\
\hline Yukon Territory & 23.0 & 20.7 & 2.3 & 0.0 \\
\hline Northwest Territories & 205.1 & 186.4 & 15.5 & 3.1 \\
\hline Nunavut & 4.4 & 3.5 & 0.7 & 0.2 \\
\hline All & & &
\end{tabular}

*Because of the small number of cases in Nunavut and Northwest Territories, the incidence rates in those jurisdictions should be interpreted with caution. 


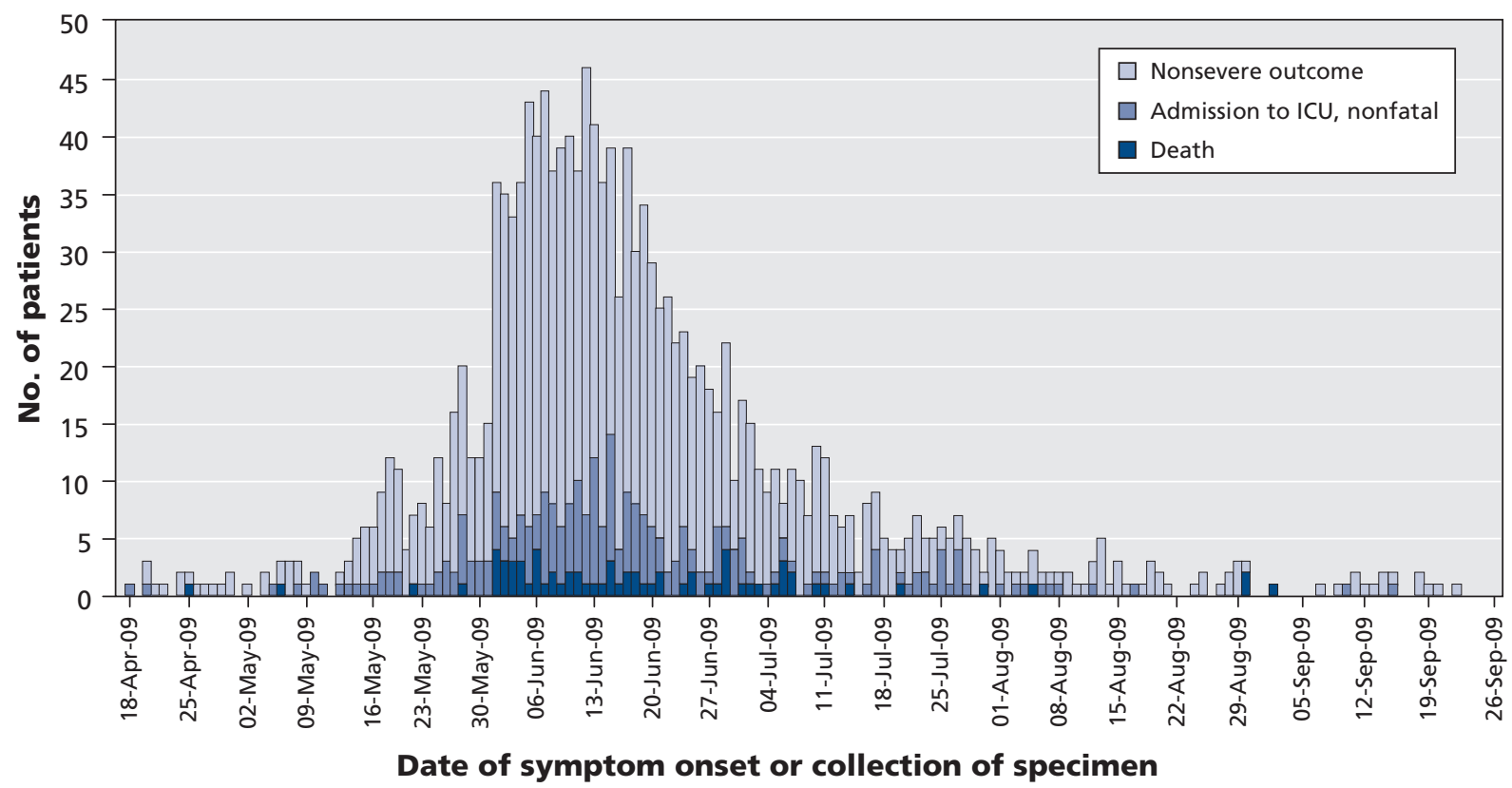

Figure 2: Epidemic curve of laboratory-confirmed cases of pandemic (H1N1) influenza in patients admitted to hospital that were reported from Apr. 26 to Sept. 26, 2009, by date of symptom onset or collection of specimen.

factor that may have contributed to the lack of elevated risk of admission to ICU among patients with lung disease. Given its prevalence in our study cohort, lung disease should continue to be viewed as an important risk factor for hospital admission among patients with pandemic (H1N1) influenza. Among patients without underlying medical conditions, the risk of severe outcomes appeared to be focused on those 30-49 years of age and patients 65 years and older. A similar demographic shift has been noted in other pandemics. ${ }^{22,23}$ We cannot rule out some age-related correlation with other conditions we did not routinely survey (e.g., obesity).

We found that the risk of a severe outcome was not greater among Aboriginal patients than among non-Aboriginal patients. However, high population-based rates of hospital admission because of pandemic (H1N1) influenza have been reported among Canadian Aboriginal people, a pattern similar to that seen in New Zealand, where Maori and Pacific peoples had higher rates of hospital admission (43.0 and 94.2 per 100000 respectively) than those of European descent (14.1 per 100 000). ${ }^{16}$ Similarly, indigenous Australians were 10 times as likely to be admitted to hospital as nonindigenous Australians. ${ }^{24}$ Demographic and clinical factors such as younger age distribution and higher prevalence of underlying conditions in Aboriginal communities may be at play; however, additional contributing factors, including the role of socio-economic and geographic factors, and possibly genetic susceptibility, need to be explored. ${ }^{25}$

Over the study period, 78 pregnant women were admitted to hospital with pandemic (H1N1) influenza. Typically, 300 pregnant women in Canada are admitted to hospital because of influenza each year, which corresponds to the rate observed among men and women 65-69 years of age. ${ }^{26}$ Clinicians may therefore expect the rate of hospital admission because of pandemic (H1N1) influenza to be higher among pregnant women than in the general population.

A delay of one day in the median time between the onset of symptoms and admission to hospital was associated with an increased risk of death. However, we did not have the information to determine whether this finding was related to a delay in treatment. A report from the United States showed that, in a multivariable model including age, vaccination status, time to hospital admission and time to antiviral treatment, the only factor associated with positive outcomes was the receipt of antiviral treatment within 48 hours after onset of symptoms. ${ }^{27}$

\section{Limitations}

We did not include probable or suspect cases of pandemic (H1N1) influenza in our analysis. In addition, our inclusion of cases from two provinces that were missing information on underlying medical conditions may have underestimated the role of such conditions in causing severe outcomes. Finally, data on Aboriginal status was not reported by two provinces.

\section{Conclusion}

The population-based incidence of admission to hospital with laboratory-confirmed pandemic (H1N1) influenza was low in the first five months of the pandemic in Canada. The risk of a severe outcome was associated with the presence of one or more underlying medical conditions, age of 20 years or more and a delay in hospital admission. The ability to gather detailed, case-based information rapidly and in a relatively uniform manner across Canada reflects an important partnership between provincial, territorial and federal public health authorities. As the pandemic evolves, continued investigation of risk factors for severe outcomes is needed to provide 
timely evidence to inform the development and updating of clinical and public health guidelines.

This article has been peer reviewed.

\section{Competing interests: None declared.}

Contributors: All of the authors contributed to the conception and design of the study and to the interpretation of the data. Alexia Campbell, Rachel Rodin, Rhonda Kropp, Julie Vachon, Zhiyong Hong and Louise Pelletier drafted the manuscript. All of the authors reviewed the article for important intellectual content and approved the final version submitted for publication.

Acknowledgements: The authors thank local, provincial and territorial surveillance partners whose exemplary work allowed for the timely collection, analysis and public health application of this important information. They also thank the management and support staff of the Centre for Immunization and Respiratory Infectious Diseases for their dedication throughout the pandemic, and the Surveillance, Epidemiology and Laboratory Task Group of the Pandemic Coordinating Committee for its scientific guidance.

Funding: No external funding was received for this research.

\section{REFERENCES}

1. World Health Organization. Global influenza programme: global surveillance during an influenza pandemic, version 1. Geneva (Switzerland): The Organization; 2009. Available: www.who.int/csr/disease/swineflu/global_pandemic_influenza surveilance apr09.pdf (accessed 2009 Sept. 1).

2. Public Health Agency of Canada. FluWatch: Definitions for the 2009-2010 season. Ottawa (ON): The Agency; 2009. Available: www.phac-aspc.gc.ca/fluwatch /09-10/def09-10-eng.php (accessed 2009 Nov. 25)

3. National Advisory Committee on Immunization (NACI). Statement on influenza vaccination for the 2008-2009 season. Can Commun Dis Rep 2008;34(ACS-3):146. Available: www.phac-aspc.gc.ca/publicat/ccdr-rmtc/08vol34/acs-3/index-eng .php (accessed 2009 Nov. 1).

4. Use of influenza A (H1N1) 2009 monovalent vaccine, recommendations of the Advisory Committee on Immunization Practices (ACIP), 2009. MMWR Recomm Rep 2009;58(RR-10):1-8.

5. Age and sex highlight tables, 2006 census. Ottawa (ON): Statistics Canada; 2009. Available: www12.statcan.gc.ca/english/census06/data/highlights/agesex/index.cfm (accessed 2009 Sept. 25).

6. Aboriginal population profile: What is the profile for the Aboriginal identity population? Ottawa (ON): Statistics Canada; 2009. Available: www12.statcan.gc.ca /census-recensement/2006/dp-pd/prof/92-594/help-aide/Q01.cfm?Lang=E (accessed 2009 Sept. 25)

7. Births 2007. Ottawa (ON): Statistics Canada, Health Statistics Division; 2009. Cat no. 84F0210X. Available: www.statcan.gc.ca/pub/84f0210x/84f0210x2007000-eng .pdf (accessed 2009 Nov. 25).

8. Pregnancy outcomes 2005. Ottawa (ON): Statistics Canada, Health Statistics Division, 2008. Cat. no. 82-224-X. Available: http://dsp-psd.pwgsc.gc.ca/collection 2008/statcan/82-224-X/82-224-XIE2005000.pdf (accessed 2009 Nov. 25).

9. Public Health Agency of Canada. Leading causes of hospitalizations, Canada, 2004 males and females combined: counts (crude rate per 100,000) [Table 2]. Ottawa $(\mathrm{ON})$ : The Agency; 2008. Available: www.phac-aspc.gc.ca/publicat/lcd-pcd97 /table2-eng.php (accessed 2010 Jan. 13).
10. Public Health Agency of Canada. Leading causes of death, Canada, 2004, males and females combined: counts (crude death rate per 100,000) [Table 1]. Ottawa (ON): The Agency; 2008. Available: www.phac-aspc.gc.ca/publicat/lcd-pcd97/table1-eng .php (accessed 2010 Jan. 13).

11. Update: influenza activity - United States, April-August 2009. MMWR Morb Mortal Wkly Rep 2009;58:1009-12. Available: www.cdc.gov/mmwr/preview /mmwrhtml/mm5836a6.htm (accessed 2009 Nov. 25).

12. Baker MG, Kelly H, Wilson N. Pandemic H1N1 influenza lessons from the southern hemisphere. Euro Surveill 2009;14. pii: 19370.

13. Bishop JF, Murnane MP, Owen R. Australia's winter with the 2009 pandemic influenza A (H1N1) virus. N Engl J Med 2009;361:2591-4.

14. US Centers for Disease Control and Prevention. Fluview: 2008-2009 influenza season week 39 ending October 3, 2009. Atlanta (GA): The Center; 2009. Available: www.cdc.gov/flu/weekly/weeklyarchives2008-2009/weekly39.htm (accessed 2009 Nov. 26).

15. Health Protection Agency. HPA weekly national influenza report, 24 September 2009 (week 39). London (UK): The Agency; 2009. Available: www.hpa.nhs.uk /web/HPAwebFile/HPAweb_C/1253205412438 (accessed Sept. 2009).

16. Baker MG, Wilson N, Huang AQ, et al. Pandemic influenza $A(H 1 N 1) v$ in New Zealand: the experience from April to August 2009. Euro Surveill 2009;14. pii: 19319.

17. 2009 pandemic influenza A (H1N1) virus infections - Chicago, Illinois, AprilJuly 2009. MMWR Morb Mortal Wkly Rep 2009;58:913-8. Available www.cdc .gov/MMWR/preview/mmwrhtml/mm5833a1.htm (accessed 2009 Sept. 1).

18. Kumar A, Zarychanski R, Pinto R, et al. Critically ill patients with 2009 influenza A (H1N1) infection in Canada. JAMA 2009;302:1872-9.

19. Shun-Shin M, Thompson M, Heneghan C, et al. Neuraminidase inhibitors for treatment and prophylaxis of influenza in children: systematic review and meta-analysis of randomised controlled trials. BMJ 2009;339:b3172. DOI:10.1136 /bmj.b3172.

20. Schanzer DL, Tam TW, Langley JM, et al. Influenza-attributable deaths, Canada 1990-1999. Epidemiol Infect 2007;135:1109-16.

21. Olson D, Heffernan R, Paladini M, et al. Monitoring the impact of influenza by age: emergency department fever and respiratory complaint surveillance in New York City. PLoS Med 2007;4:e247.

22. Taubenberger JK, Morens DM. 1918 influenza: the mother of all pandemics Emerg Infect Dis 2006;12:15-23.

23. Henderson DA, Courtney B, Inglesby TV, et al. Public health and medical responses to the 1957-58 influenza pandemic. Biosecur Bioterror 2009; 7:265-73.

24. Australian Government Department of Health and Ageing. Australian influenza surveillance summary report, no. 21, 2009, reporting period: 26 September 20092 October 2009. Canberra (Australia): The Department; 2009. Available: www .healthemergency.gov.au/internet/healthemergency/publishing.nsf/Content/18D06 BAC4644C98DCA25763E00823442/\$File/ozflu-no21-2009.pdf (accessed 2009 Nov. 26)

25. Diabetes among Aboriginal (First Nations, Inuit and Metis) people in Canada the evidence. Ottawa (ON): Health Canada; 2005. Available: www.hc-sc.gc.ca /fniah-spnia/pubs/diseases-maladies/_diabete/2001_evidence_faits/sec_2-eng.php\# diabetes_among_aboriginal_people (accessed 2010 Jan. 13).

26. Schanzer DL, Langley JM, Tam TW. Influenza-attributed hospitalization rates among pregnant women in Canada 1994-2000. J Obstet Gynaecol Can 2007;29:622-9.

27. Hackett S, Hill L, Patel J, et al. Clinical characteristics of paediatric H1N1 admissions in Birmingham, UK. Lancet 2009;374:605.

Correspondence to: Dr. Rachel Rodin, Public Health Agency of Canada, Rm. 265A, 130 Colonnade Rd., Ottawa ON K1A 0K9; rachel_rodin@phac-aspc.gc.ca 